Res Publica. Revista de Historia de las Ideas Políticas ISSN: 1576-4184

\title{
La concepción del cuerpo de los esclavos y dependientes en el mundo griego*
}

\author{
Domingo Plácido**
}

Recibido: 20 de enero de 2017 / Aceptado: 14 de julio de 2017

Resumen. La consideración del cuerpo de los diferentes individuos que forman la sociedad aparece como un espejo de la consideración de las personas en cada momento. El cuerpo se caracteriza muy pronto como antítesis de la vida espiritual que sirve para definir a la persona plenamente considerada y con pleno derecho. Los cambios afectan al campesino dependiente hasta que se impone la esclavitud mercancía, que marca la mayor alteridad entre los humanos. Dentro de tal consideración, se detectan importantes síntomas de evolución hasta la dominación romana.

Palabras clave: Historia del cuerpo; Grecia; esclavitud.

\section{[en] The Conception of the Body of Slaves and Dependents in the Greek World}

\begin{abstract}
The image of body of the individuals who mould society seems like a mirror of the idea of persons in every moment. The body is characterized very early as a antithesis to spiritual life who defines the person plenty considered and with all the rights. Changes affect to peasant subjected till chattel slavery is imposed, which marks maxim alterity between human beings. Inside such idea, symptoms of evolution are detected until roman domination.
\end{abstract}

Keywords: History of the body; Greece; slavery.

Sumario: 1. El cuerpo del esclavo y el cuerpo del libre. 2. El cuerpo del campesino libre, 3. El desarrollo de la esclavitud. 4. La utilización del cuerpo del esclavo en el derecho penal. 5. El cuerpo como marca. 6. El cuerpo y el estatuto legal. 7. El cuerpo como tumba $(\sigma \tilde{\omega} \mu \alpha / \sigma \tilde{\eta} \mu \alpha)$. 8. Los efectos de la crisis. 9. La visibilidad del esclavo. 10. La estabilidad social helenística. 11. Conclusión.

Cómo citar: Plácido, D. (2017). La concepción del cuerpo de los esclavos y dependientes en el mundo griego, en Res publica 20.3, 477-492.

\footnotetext{
* Agradezco a los evaluadores las indicaciones que me han servido de gran utilidad.

** Universidad Complutense de Madrid

placido@ghis.ucm.es
} 
Men are the sport of circumstances, when the circumstances seem the sport of men Lord Byron, Don Juan, V 17, 135-135

\section{El cuerpo del esclavo y el cuerpo del libre}

Entre las ventajas de los griegos destaca la esclavitud, que les permitía dedicarse a formar su cuerpo y su espíritu ${ }^{1}$. Tal concepción responde a una tradición tanto moderna como antigua. El clasicismo moderno creía que los griegos controlaban la realidad, pero Byron ya sabía que todos los humanos han estado controlados por ella. La penetración en ésta en profundidad permite observar cuáles eran los límites de las virtudes que se les atribuyen. La capacidad de algunos de dedicarse al cultivo del cuerpo tenía unos costes que no sólo afectaban a las víctimas, sino también a las limitaciones intelectuales que ello trae consigo.

Evidentemente, Humboldt trata del cuerpo del ciudadano, el que puede ejercitarse en los gimnasios y mostrarse desnudo con orgullo en las pruebas atléticas, relacionadas con el acceso a la ciudadanía, las prácticas militares y la relaciones homoeróticas, tanto entre jóvenes en formación como entre éstos y sus pedagogos, equivalentes en este sentido a pederastas. La afirmación de Humboldt revela en cualquier caso que, en su visión del mundo griego, existían dos concepciones diferentes del ser humano y que el cultivo del cuerpo por los libres se basa en la existencia de los esclavos, es decir, de otros cuerpos que, no sólo no tienen acceso a las prácticas del cuerpo y del espíritu que hacen admirables a los griegos, sino que además se hallan cosificados para permitir que se extraiga de ellos la posibilidad de las prácticas propias del hombre libre.

La Antropología suele considerar que los cuerpos del pasado prehistórico permanecían carentes de individualización, lo que sigue pasando con el cuerpo del escla$v^{2}$. El desarrollo del individuo como persona se caracterizó por la introducción del alma ${ }^{3}$, lo que significaba un alejamiento de la naturaleza, por lo que, según Aristóteles, para definir al esclavo importa sólo el cuerpo, como se ve en Política I 5, $8=$ $1254 \mathrm{~b} 15^{4}$ :

Aquellos hombres que se diferencian de los demás tanto como el alma del cuerpo o como el hombre de la bestia (se hallan en esta condición aquellos cuya función se limita al uso de su cuerpo y esto es lo mejor que tienen), son esclavos por naturaleza y para éstos es mejor estar sometidos a este tipo de autoridad, como en los casos mencionados.

\footnotetext{
W. von Humboldt, Historia de la decadencia y ocaso de los Estados libres griegos y otros textos sobre la Antigüedad clásica, ed. de S. Mas, Madrid-México, CSIC-PyV, 2010, p. 72.

2 C. Fowler, The Archaeolgy of Personhood. An Anthropological Approach, Londres \& Nueva York, Routledge, 2004, p. 3.

Ibidem, p. 14.

4 Las traducciones de la Política de Aristóteles son de P. López Barja de Quiroga y E. García Fernández, Madrid, Istmo, 2005.
} 
En los cambios, los dones e intercambios se llega a producir la entrega del cuerpo $^{5}$, lo que se ampliaría a escala general con el desarrollo de la esclavitud mercancía. Polieno, en Estratagemas I 34, 2, referida a Cimón, dice que, en el momento de la elección entre cuerpos desnudos y objetos en el botín, los aliados eligieron éstos y los atenienses los cuerpos, mucho mejor elección debido a los rescates, comenta el autor. Los cuerpos de los hombres cautivos funcionarán como objeto de los repartos del botín en plena época del Imperio ateniense.

\section{El cuerpo del campesino libre}

En los orígenes del Arcaísmo, cuando se definen las sociedades campesinas en torno a la formación de la pólis, el mundo rural se estructura a base del establecimiento de relaciones de reciprocidad y relaciones de dependencia que definen la complejidad del momento. Los campesinos, concretamente los pastores, se definen en la intervención de las Musas, como simples vientres, en Hesíodo, Teogonía 26-28. West ${ }^{6}$ compara la cita con Homero, Odisea XVIII 53-54, donde Odiseo, disfrazado de viejo, responde al reto de Antínoo que, a pesar de todo, acepta por impulso del "vientre

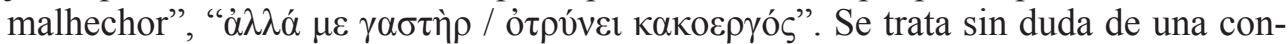
notación negativa de dicha parte del cuerpo, que denigra en Hesíodo al trabajador dependiente. También cita West a Longo IV 11, 2, que trata de un personaje acos-

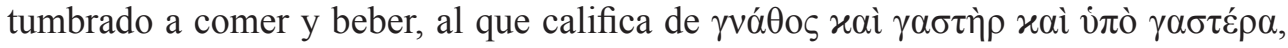
"mandíbula, vientre y bajo vientre", que J.-R. Villefonde ${ }^{7}$ explica a través de un frag-

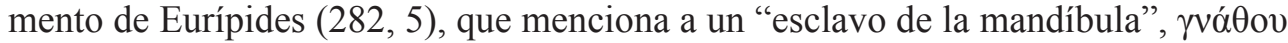
$\delta$ oṽ ${ }_{0}$. Las metáforas, aunque más tardías, tienden a devaluar el cuerpo de las clases dependientes o a identificarlos con ellas. Su inferioridad es diferente, pero se muestra a través de las necesidades del cuerpo, que se convierte en símbolo de la relación social que más tarde se enunciará teóricamente en diferencias funcionales. En una época en la que la esclavitud no se había desarrollado plenamente como mercancía, como es la época de Hesíodo, aunque ya hay esclavos y esclavas en los palacios y en las tierras del campesinado, el cuerpo del campesino se halla ya cosificado. Son los mismos que aparecen como semisalvajes en la poesía aristocrática.

Es el caso de las menciones del poeta Teognis, 53-58, que advierte a su pupilo,

Cirno, esta ciudad es aún una ciudad, pero sus habitantes son ahora distintos: antes, no conocían ni el derecho ni las leyes, sino que en torno a su cuerpo vestían pieles de cabra hasta romperlas y se apacentaban, al igual que los ciervos, fuera de la ciudad. Éstas son hoy las gentes de bien, oh Polipaides; y los buenos de antes, ahora son los villanos: ¿quién es capaz de soportar este espectáculo??

En la sociedad aristocrática en que predominan las relaciones clientelares, los dominantes identificaban a los campesinos dependientes con el cuerpo de los animales.

C. Fowler, op. cit., p. 55.

6 M. L. West, Hesiod. Theogony, Oxford, Clarendon Press, 1966, ad loc., cita en su comentario Longo, IV 11; Homero, Odisea XVIII 53.

Ad loc., París, Les Belles Lettres (CUF), 1987.

8 Traducción de F. Rodríguez Adrados, Barcelona, Alma Mater, 1959. 
Las transformaciones que se operan en el Arcaísmo con el desarrollo de la pólis darán lugar al reconocimiento como persona de tales dependientes, en la formación de la ciudadanía, que sirve para garantizar la libertad de las poblaciones, paralelamente el desarrollo del trabajo servil, que no se produce de modo homogéneo en todas las ciudades. El poeta Teognis, que ve con disgusto el cambio que se produce en sus tiempos en la sociedad, con la irrupción de las tiranías, participa de la mentalidad aristocrática, que reacciona ante la extensión en los derechos de ciudadanía de los que para ellos son identificables con animales.

\section{El desarrollo de la esclavitud}

Con el desarrollo de la esclavitud, la conciencia del cuerpo dependiente se concreta en el esclavo y se endurece en la ciudad, paralelamente a la liberación del campesinado. En este proceso, Solón incluye en sus reformas la eliminación de la necesidad de responder con el "cuerpo" de las deudas contraídas en los procesos marcados por la diferenciación social que tiene lugar en los momentos dramáticos del Arcaísmo. El cuerpo como prenda es un paso a la esclavización. El desarrollo paralelo de la moneda facilita el proceso por el que al tiempo que unos se cargan de deudas otros puedan facilitar la creación de los mercados de esclavos, proporcionados al mismo tiempo por medio de la guerra. Se trataría de la creación de un sistema militar, monetario y esclavista ${ }^{9}$. Guerra, dinero y esclavos constituyen los fundamentos de una sociedad que convierte en mercancía el cuerpo de una parte de la humanidad.

Antes de las reformas de Solón, el cuerpo del campesino identificado con su persona se podía convertir en propiedad de los acreedores. La teórica reciprocidad de la sociedad campesina, al desarrollarse diversas formas de desigualdad, se convierte en un modo de coacción, dado que la única manera de responder a las "gracias" o "favores" del poderoso, la única cháris que puede ofrecer a cambio, es su propio cuerpo, es decir la servidumbre de su persona. Es la forma de servidumbre que se suele conocer como "esclavitud por deudas", la que define las sociedades clientelares. Con las reformas de Solón, no sólo queda abolida esta forma de servidumbre, practicada entre miembros de la misma comunidad de los atenienses, así como en otras ciudades en formación, sino que además se define el concepto de ciudadanía como comunidad con derecho a quedar exenta de tales dependencias, lo que se complementa con la definición del esclavo mercancía, de procedencia externa, con tendencia a identificarse con el bárbaro. De este modo se facilita el proceso de cosificación del esclavo, cuando el aprovisionamiento de mano de obra se ve favorecido por el desarrollo de las relaciones exteriores, la consolidación del proceso colonial y el impulso de las actividades mercantiles. El esclavo es un cuerpo objeto de tales actividades, una mercancía, que no participa de la naturaleza humana identificada con la helenidad o incluso con la ciudadanía.

La ciudad democrática marca un abismo entre los libres y los esclavos, éstos procedentes del exterior, en principio de los bárbaros, de modo creciente en la época inmediatamente posterior a las Guerras Médicas. Es significativo el mismo

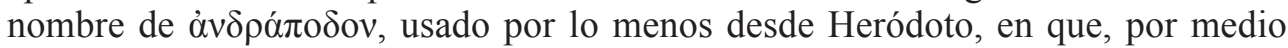

D. Graeber, Debt. The First Five Thousand Years, New York, Melville, 2011, p. 229. 
de una formación bastarda, se equipara el esclavo al $\tau \varepsilon \tau \rho \alpha ́ \pi$ o $\delta o v$, el "cuadrúpedo", en una metáfora cruel como la que utilizará Varrón, instrumentum uocale (De agricultura, I 17, 1). Lo mismo ha querido expresar Aristóteles, Política, I 4, 2-3=

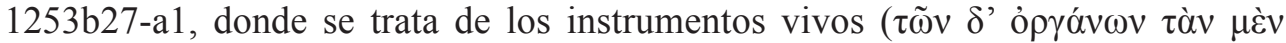

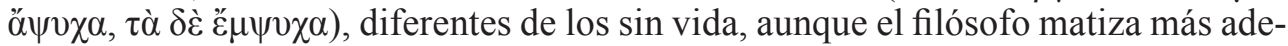
lante $(5=1254 \mathrm{a} 7-13)$ para aclarar que puede haber hombres que sólo tienen de libres el cuerpo. La cosificación del cuerpo es total. Heródoto, III 125, se refiere al final dramático del tirano de Samos, Polícrates. Cuenta que Oretes, el sátrapa de Sardes, tras crucificar al tirano, dejó libres a los samios, pero a los extranjeros y esclavos

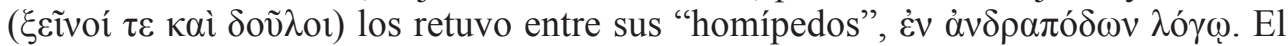
persa actuaría de acuerdo con lo que va imponiendo en la Grecia del momento, en un comportamiento que se relaciona con la actitud persa de tratar como no libres a todos los súbditos ${ }^{10}$. Ello no es sorprendente dado que es el testimonio más claro de la imposición del sistema por el que se generaliza la explotación de los cautivos en principio con los bárbaros. El término $\delta$ oṽ $\lambda$ o $\varsigma$ en cambio se hereda desde las formas de esclavización interna, especificada como "esclavitud por deudas" en las medidas de Solón. Tal parece ser el significado del micénico do-e-ro como dependiente de los palacios.

\section{La utilización del cuerpo del esclavo en el derecho penal}

Los esclavos no tienen más personalidad que la que les proporciona su cuerpo, tanto en la explotación del trabajo como en la vida cívica. En la ciudad democrática se impone en la práctica judicial el uso de la tortura como único modo de admitir el testimonio de los esclavos. Antifonte es el autor que proporciona mayor número de ejemplos significativos, no sólo de las prácticas, sino también sobre los debates acerca de la validez y eficacia del sistema. El orador defiende el uso de la tortura con los esclavos para conocer la verdad, pero a veces duda de que el esclavo pueda decir la verdad o declarar falsamente para librarse de la tortura. En el discurso I, Acusación de envenenamiento contra la madrastra, 7, atribuye importancia decisiva al testimo-

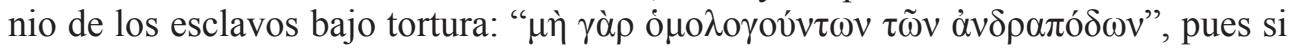
no hay acuerdo entre los esclavos la reo podría quedar libre. La falta de acuerdo de los esclavos bajo tortura sería un argumento definitivo. En el mismo discurso, I 10, el orador pide a los contrincantes que procedan ellos mismos a la tortura, para que los esclavos no se viesen forzados, pero la tortura debía forzarlos a denunciar lo que había pasado si no se ponían de acuerdo: $\mu$ ò ó o $_{\text {o }}$ ovó $\mu \varepsilon v \alpha$. Da la impresión de que la validez aparece como secundaria con respecto a la coincidencia primera de los testimonios. Pero, según confiesa en I 12, quien libra sus esclavos a la tortura se hace su propio juez. Aristóteles, en Retórica, I 15=1376b31-77a6, a pesar de que señala algunos problemas del procedimiento, se inclina claramente en favor del uso de la tortura, aunque un texto (77a7) considerado corrupto añade algunas consideraciones críticas, sobre la capacidad de resistencia o la debilidad de los torturados, lo que podría condicionar sus reacciones.

10 D. Plácido, "La douleía en Heródoto: imperialismo persa y relaciones de dependencia", Tês philies táde dôra. Miscelánea léxica en memoria de Conchita Serrano (Manuales y Anejos de “Emerita”-XLI, Madrid, C.S.I.C., 1999, pp. 681-688. 
En el discurso V Sobre el asesinato de Herodes, la mayor parte está dedicada a la interrogación del esclavo. El libre que es interrogado es también sometido a la tortura, pues no es seguro que sea libre. Hay ejemplos de otros libres en la misma situación, pero se trata de personas muy cercanas al estatuto servil. En el texto la situación no está clara (42). De hecho, la tortura los persuade para poner al testigo de parte de quien la pone en práctica $(30,31,33,50)$. A partir de 75 se ha considerado que el acusado, Euxiteo, es un oligarca ${ }^{11}$ defendido por Antifonte contra el cleruco ateniense. Se revela así el trasfondo social y político del discurso. A partir de V 31, se desvela que el esclavo tenía sin duda la promesa de la libertad. Dependía de sus adversarios que la tortura cesase y naturalmente quería librarse del interrogatorio $^{12}$. Si el que hace el interrogatorio es el dueño individual del esclavo, las posibilidades de manipulación son muy fuertes, dado que puede prometer la libertad e incluso hacer cesar la tortura. El orador trata de hacer comprender que el retraso era a propósito para inducir al esclavo a la falsedad ${ }^{13}$. En V 40, el autor se lamenta de que el esclavo, cuando fue sometido a la rueda de la tortura, bajo coacción, "se puso a acusarme en falso, para liberarse del interrogatorio". La cuestión es si el testimonio del esclavo vale más si declara bajo tortura o libremente ${ }^{14}$. Declara más adelante, V 52: "Yo habría hecho desaparecer a los dos individuos, si hubiese cometido el acto", pero, contra la evidencia y a pesar de la tortura, "ellos me acusan". La deducción lógica es que la tortura no vale nada, pero se mantiene en el terreno judicial. Añade en V 54: "Ellos dicen que hay un escrito que difiere de la declaración del esclavo sometido a la tortura"; la voluntad del orador es negar el testimonio del esclavo ${ }^{15}$, frente a la carta ${ }^{16}$. En VI Sobre el coreuta, 23, en relación con los esclavos, limitarse al interrogatorio dependía de que el testimonio le pareciera verídico, "si no, yo estaba dispuesto a librar a la tortura a todos los míos, y si él reclamaba que no fuese yo, me comprometía, tras haber obtenido autorización del dueño, a librarlos para que él los pusiese en la tortura de la manera que quisiera”. Es evidente que, a pesar de todo, la tortura seguía siendo un instrumento legal considerado válido contra todas las críticas aquí implícitamente presentes. Sólo se explica a partir de una consideración nula del cuerpo de los esclavos, aunque el autor reconoce que los esclavos pueden tomar sus decisiones a favor de sus propios intereses.

Licurgo, Contra Leócrates, 28-35, se manifiesta también totalmente favorable al uso de la tortura para obtener el testimonio de los esclavos como prueba judicial. En este caso propone someter a los esclavos del acusado. Rechazarlo sería como confesar la culpa. Para él es justo y democrático someterlos a tortura. También Iseo, VIII 10, La sucesión de Cirón, consideraba que el uso de la tortura daría más confianza a

G. Ramírez, "El trasfondo político en los discursos de Antifonte”, Polis, 8, 1996, pp. 233-246, aquí p. 241.

12 "Euxitheus dwells at length on alleged irregularities in the interrogation. But although strict rules applied to an interrogation that resulted from a challenge by one litigant to the other (1.6n), these rules did not apply to interrogation during a criminal investigation, especially when the slave was suspected of involvement in the crime. Nonetheless, Euxitheus' complaints may raise doubts about the prosecution's motives" (M. Gagarin, Antiphon \& Andocides, Austin, University of Texas Press, 1998, p. 58).

13 M. Gagarin, The Murder of Herodes. A Study of Antiphon 5, Frankfort, P. Lang, 1989, p. 71.

14 M. Gagarin, Antiphon \& Andocides, op. cit., p. 60.

15 M. Gagarin, Antiphon the Athenian: Oratory, Law and Justice in the Age of Sophists, Austin University of Texas Press, 2002, pp. 157-158. Ésta es la estrategia general del discurso (pp. 25-63)

16 M. Gagarin, Murder, op. cit., p. 81. 
los jueces. Se establecería mejor la verdad así de los testimonios de los esclavos que de los libres (12). Es sospechoso que se niegue a ello (13).

\section{El cuerpo como marca}

Pseudo Jenofonte, Constitución de los atenienses I 10, se queja de que en Atenas la democracia había borrado las diferencias entre los esclavos y los libres, al subir a la condición de ciudadanos a muchos de los que hacían trabajos serviles, mientras que la diferencia en Esparta estaba clara y por ello era fácil castigarlos físicamente sin confundirse, con el riesgo de castigar a un ciudadano. Sin embargo, en las pinturas en general el esclavo no se distingue del libre por razones físicas ${ }^{17}$, aunque hay algún negro en pinturas del Pintor de Copenhague de 470 a.C. ${ }^{18}$. Asimismo, hay imágenes de negros esclavos en algunos alabastros, por ejemplo, en uno de 480 a.C. ${ }^{19}$. Es más frecuente que el esclavo esté señalado como una figura diminuta ${ }^{20}$. Parecería que, a principios del siglo IV, al menos algún oligarca se atreve, como se ve en el ejemplo de Contra Loquites de Isócrates, XX, a maltratar a los que tienen aspecto de dependientes. En gran medida, se estaba cumpliendo la profecía del Pseudo-Jenofonte, I 9, en el sentido de que sin democracia los pobres caerían en la esclavitud. La democracia no ha elevado a los esclavos, sino permitido ser ciudadanos libres con derechos a los que se identifican normalmente como dependientes, al estilo de los hilotas espartanos, o todos aquellos que tienen "nombres de libres aunque son esclavos"21. Se trata de un uso funcional, como el que hará Aristóteles, cuando se refiera a los que hacen trabajos serviles. En un mundo donde los thêtes se han convertido en ciudadanos activos, la concepción del cuerpo adquiere un estatuto claramente ambiguo.

Lisias escribe a principios del siglo IV el discurso XXIII, Contra Pancleón, para atacar a alguien que trabajaba en el batán y pretendía ser plateense del demo de Decelia y, por tanto, disfrutar de la ciudadanía, pero el orador comprueba que nadie de los de Decelia lo conocía y creían que era meteco, aunque le dicen que era un esclavo fugitivo, como atestigua su propietario Nicomedes; el demandante había creído que era meteco, pero ni siquiera era libre; tenían derecho a apropiárselo y de hecho apareció una mujer que pretendía ser su dueña. El caso es reflejo de las circunstancias de una época en que la personalidad jurídica se ve debilitada ante los intentos de extender las posibilidades de explotar la personalidad de quienes se hallan en situación de inferioridad por uno u otro motivo.

El citado discurso de Isócrates XX (Contra Loquites), se pronunció igualmente en los primeros años del siglo IV, entre 400 y 396. Se trata de un individuo que ha sido golpeado por un rico. "Son más graves los daños corporales que los que afectan a la riqueza, porque combatimos por la libertad y luchamos por la democracia" (1). "Hay que valorar la defensa del cuerpo más que la riqueza". Se manifiesta la nece-

\footnotetext{
R. Osborne, The History Written on the Classical Greek Body, Cambridge University Press, 2011, p. 107.

Ibidem, p. 130, fig. 5.2.

Ibidem, p. 138, fig. 5.10.

Ibidem, p. 133.

D. Plácido, “«Nombres de libres que son esclavos...» (Pólux, III, 82)”, Esclavos y semilibres en la Antigüedad clásica, Madrid, Universidad Complutense, 1989, pp. 55-79.
} 
sidad de los pobres de defenderse de los abusos de los ricos, al final de la guerra del Peloponeso. "Hay que valorar la defensa del cuerpo más que la riqueza. El derecho debe entenderse como protección de la persona y no de la propiedad". El debate se centra en la salvaguarda de las propiedades o de las personas, aunque sólo cuenten como patrimonio con su cuerpo.

\section{El cuerpo y el estatuto legal}

Desde el principio del Pluto de Aristófanes se pone de relieve el papel de la riqueza, como daímon, en la posibilidad de poseer el propio cuerpo, que se hace propiedad de quien lo compra (6-7), con lo que se revela el problema del momento, que ha aumentado el número de esclavos por necesidad. Se trata de las realidades que sustentan las teorías de Aristóteles, ya que se hace dependiente quien se ve obligado a realizar trabajos serviles.

En la misma línea se organiza la teoría de la sociedad en la obra de Platón, República, 370e-371e 2 :

- Sin embargo, dije yo, establecer la misma ciudad en un lugar tal en que no haya necesidad de importaciones, es algo casi imposible.

- Imposible en efecto.

- Necesitarán además por tanto otros, que traigan allí desde otra ciudad lo que hace falta.

- Los necesitarán.

- Pero si el servidor va de vacío y no lleva nada de lo que necesitan aquéllos de parte de los que va a traer lo que para ellos es necesario, volverá de vacío, ¿eh?

-Me parece a mí

-Entonces es necesario no sólo hacer los productos de casa suficientes para ellos mismos, sino también los tipos de producto y las cantidades para aquéllos que los necesiten.

-En efecto, es necesario.

-Entonces necesitamos para la ciudad más agricultores y más de los otros trabajadores.

-Más desde luego.

-Y también de los otros servidores que lleven y traigan cada mercancía. Éstos son comerciantes, ¿no?

-Sí.

-Y necesitaremos comerciantes.

- Claro.

-Y si se hace comercio por mar, habrá necesidad de muchos otros de los que conocen las labores marítimas.

-De muchos otros, desde luego.

- ¿Y qué?, ¿en la misma ciudad, cómo intercambiarán unos con otros lo que cada uno fabrique? Pues es por lo que formamos una comunidad y habitamos una ciudad.

\footnotetext{
22 Traducción propia.
} 
-Es evidente, dijo él, vendiendo y comprando.

- Tendremos el ágora y la moneda como signo para el intercambio a partir de esta situación.

- Claro.

- ¿Acaso si el campesino que trae al ágora lo que produce, o algún otro de los trabajadores, no llega en el mismo momento que los que necesitan intercambiar lo que él produce, perderá el tiempo de su propio trabajo sentado en el ágora?

-De ninguna manera, dijo él, sino que están los que al ver esto se encargan ellos mismos de tal labor, en las ciudades bien administradas aproximadamente los más débiles de cuerpo e incapaces de hacer cualquier otro trabajo. En efecto, es necesario que permanezcan allí para cambiar por dinero a los que necesiten vender y para dar por dinero a los que necesiten comprar.

-Esta es en efecto, dije yo, la necesidad que os impulsa en la ciudad el nacimiento de tenderos. ¿O no llamamos tenderos a los que se dedican a la compra y a la venta asentados en el mercado y mercaderes a los que viajan a las ciudades?

-Desde luego.

- Además hay algunos otros servidores, según yo pienso, que en lo que afecta a la inteligencia no son muy dignos de estima, pero tienen la fuerza del cuerpo suficiente para los trabajos; los cuales, al vender la utilidad de su fuerza, al llamar a este precio salario, se llaman, según yo creo, asalariados, ¿no?

-Desde luego.

- Masa de la ciudad son, según parece, los asalariados.

-Así me parece.

En el texto platónico se refleja la tendencia a establecer una distribución del trabajo acorde con las capacidades del cuerpo; los más débiles serían los encargados de las transacciones monetarias asentados en los mercados, que se diferencian de los que son capaces de otros trabajos para los que se necesita fuerza. El cuerpo adquiere pues una funcionalidad específica en la distribución social del trabajo, siempre al margen de los dominantes.

\section{El cuerpo como tumba $(\sigma \tilde{\omega} \mu \alpha / \sigma \tilde{\eta} \mu \alpha)$}

Platón, Crátilo, 402b-c, le atribuye a Orfeo unos versos sobre Océano y Tetis comparados con los de Hesíodo, Teogonía, 337, y Homero, Ilíada, XIV 201 (DK1B2). Y en 400b-c, el contexto órfico se revela en la idea del cuerpo (sôma) como tumba (sêma) del alma (B3), llegada a través de los pitagóricos, como se ve en Filolao (DK44B14). Expresa el mismo Platón que esta referencia recoge el pensamiento órfico, vinculado en su origen a las clases dependientes, que buscan el consuelo en la pervivencia del alma más allá de la muerte del cuerpo, que no es más que la tumba, situación paradójica de que se libera al desprenderse de él ${ }^{23}$. Por ello la vida es muerte y la muerte es vida. En las duras relaciones de dependencia, acentuadas en el siglo IV al ampliarse los grupos dependientes más allá de la esclavitud legal, al caer ésta en un proceso de indefinición que facilita la sumisión de capas de población libre por el hecho de

3 G. Thomson, Aeschylus and Athens, Londres, Lawrence \& Wishart, 19462, p. 157. 
verse forzada al trabajo servil, el pensamiento idealista recibe un fuerte impulso consolatorio, que asume el pensamiento platónico como modo de justificación de la realidad, sobre todo cuando ésta se plantea como abocada a la nueva estructura que configurará la realidad social del Helenismo.

Naturalmente, la fuente principal de la esclavitud mercancía sigue siendo la guerra, que en siglo IV se caracteriza por practicarse sobre todo entre griegos, lo que desbarata definitivamente la teoría de que se trataba de algo derivado de la condición de bárbaro. Así ocurre con los cuerpos de los prisioneros en Demóstenes, XX Contra Leptines 77, que se refiere a las acciones de Cabrias contra los lacedemonios en 376, en las que entre otros logros aportó tres mil prisioneros, denominados como "cuer-

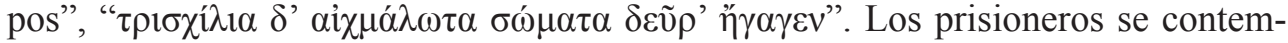
plan como "cuerpo", $\sigma \omega ́ \mu \alpha \tau \alpha$, aunque sean griegos. En estos momentos de luchas entre ciudades, la esclavización deja de limitarse a los bárbaros ${ }^{24}$.

Demóstenes, LVII, Contra Eubúlides, habla en favor de Euxiteo al que han excluido del demo de Halimunte. Tiene que demostrar que sus padres legítimos son ciudadanos a base de testimonios. El padre tiene acento extraño porque ha sido vendido como esclavo en la Guerra del Peloponeso (18). En efecto, en el año 346 la revisión de la ciudadanía ha conducido a los condenados a ser vendidos como esclavos ${ }^{25}$. La consecuencia de tales indefiniciones es que cualquiera puede ser considerado esclavo por haberse encontrado en situación precaria.

El mismo Demóstenes, LIX, Contra Neera, 113, aparece preocupado por el hecho de que la pobreza pueda servir de vehículo a la esclavización de mujeres ${ }^{26}$. La necesidad parece afectar más directamente a las mujeres, más vulnerables en general, dentro de la sociedad ateniense, a sufrir intentos de explotación.

\section{Los efectos de la crisis}

En el siglo IV la democracia se considera, o bien como el ámbito donde los pobres pueden ser libres, o bien como el ámbito en que sólo toman parte los poseedores. Ésa es la clave de la crisis de la ciudad. Por ello, la naturaleza que se considera propia del esclavo es no sólo la que se deriva de la guerra o el comercio, que es la que define al esclavo como cautivo o como artículo de mercado, lo que normalmente se relaciona con la naturaleza del bárbaro, sino la de todos aquéllos cuya actividad está limitada por el uso de sus cuerpos (Aristóteles, Política, I 5, 8=1254b15). La "Naturaleza" se convierte en la forma de definir la realidad económica, en la que una parte de la población sólo realiza trabajos físicos. Por ello, Osborne considera que la esclavitud por naturaleza es una invención de Aristóteles ${ }^{27}$. Es por naturaleza esclavo el que está más dotado por la naturaleza para obedecer por medio de su cuerpo. Es por naturaleza dueño el que está más dotado en su inteligencia para

24 D. Plácido, "La esclavitud de griegos cautivos durante el período de la crisis de la ciudad estado", en Mª L. Sánchez León, G. López Nadal, eds., Captius i esclaus a l'antiguitat i al món modern, Nápoles, Jovene, 1996, pp. 11-20.

25 B. Manville, The Origins of Citizenship in Ancient Athens, Princeton University Press, 1990, p. 175.

26 D. Plácido, "La mujer en el oîkos y en la pólis: formas de dependencia económica y de esclavización", en F. Reduzzi, A. Storchi, Femmes-esclaves. Modèles d'interprétation anthropologique, économique, juridique, Diáphora, 9, Nápoles, Jovene, 1999, pp. 13-19, aquí p. 19.

27 R. Osborne, History, op. cit., p. 138. 


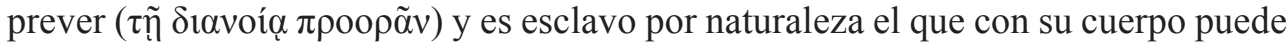
actuar. La mujer y el esclavo se diferencian por naturaleza, pero no entre los bárbaros, porque ellos son todos esclavos, en la idea de que bárbaro y esclavo es lo mismo (I 2, 1-4=1252a24-b9). Aristóteles pretende conservar las tradiciones de la pólis dentro de las nuevas condiciones históricas, cuando en realidad aumentaba la esclavización entre griegos por las guerras, al tiempo que se iban deteriorando las condiciones por las que los ciudadanos conservaban la libertad con la expansión de formas de explotación que afectaban a los griegos y a los ciudadanos. La ciudadanía dejaba de proteger, hecho que se consolida con la implantación de los regímenes despóticos.

En definitiva, mujeres y niños fueron las víctimas más directas de la crisis de la esclavitud mercancía en el siglo IV y de la sumisión a dependencia de "ciudadanos". Mujeres y niños eran ya ciudadanos de segunda y están en peores condiciones cuando se trata de conservar la libertad. Las mujeres y los hijos aparecen como los servidores del pobre, en Aristóteles, Política, VI 8, 23 (=1323a5-6). La sumisión de las mujeres de la familia también queda clara en Memorables, II 7, 7-10, de Jenofonte, dentro de los consejos que Sócrates dedica a Aristarco acerca de la organización de la casa. En el ô̂kos el teórico protagonismo de las mujeres no es más que un modo de subordinación debida su condición de objeto dedicado a la reproducción del sistema. Ello justifica la posición atribuida al cuerpo de las mujeres en la escala social.

Según Aristóteles, en el texto citado, Política, I 5, 8-9 = 1254b16-21, es por naturaleza esclavo el que puede ser de otro y el que es de otro (I 5, $9=1254 \mathrm{~b} 20-22$ ), esclavos y animales domésticos con su cuerpo sirven de ayuda igualmente (b25-26). Para los que tienen cuerpo y alma de esclavos lo justo es ser esclavos $(11=1255 \mathrm{a} 2)$. El esclavo es parte del dueño y por ello conviene que haya philía $(6,10=$ b11-13), donde se revela con toda crudeza el aspecto de la "amistad" como relación desigual, que en Roma se identificará, como amicitia, con las relaciones clientelares ${ }^{28}$. La autoridad política se distingue de la del dueño porque es sobre libres e iguales (7, $1=1255 \mathrm{~b} 20)$. La posesión de esclavos es como la guerra o la caza $(7,5=$ b39). El esclavo es parte de la posesión, $\tau \tilde{\eta} \varsigma \kappa \tau \eta ́ \sigma \varepsilon \omega \varsigma(8,1=1256 \mathrm{a} 2)$. La guerra sirve para obtener como propiedad a los hombres hechos para obedecer $(8,12=1256 \mathrm{~b} 25)$. Son los elementos clave de la definición de la dependencia en el pensamiento aristotélico, factor fundamental para entender en su complejidad la evolución social de Atenas tras el final de la guerra del Peloponeso, cuando la cosificación del cuerpo del esclavo rompe los límites para ampliarse a todo el que se ve obligado de emplearlo al servicio de otro. Pero el concepto de posesión aplicado al esclavo también aparece fuera del pensamiento aristotélico, por ejemplo, en la tragedia. En la Medea de Eurípides, verso 49, el Pedagogo se dirige a la Nodriza con estas palabra: " $\pi \alpha \lambda \alpha$ iòv

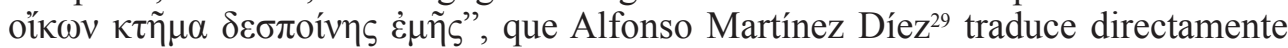
como "antigua esclava de la casa de mi señora", Francisco Rodríguez Adrados ${ }^{30}$

28 Cf. por ejemplo, L'amicizia e le amicizie. Atti del V Congresso Internazionale di Studi Antropologici (Palermo, 24-26 novembre 1983), Palermo, Siace, 1984; Texte, politique, idéologie, Actes de la Table Ronde 1975, Besançon, 4 mars 1975, París, Les Belles Lettres, 1976, con algunos trabajos específicos, como los colectivos sobre "Affectivité et dépendance" (313-319) o sobre "Crise et rupture de l'amicitia" (329-333) ; y, dentro del Congreso de Palermo citado, la intervención de Antonino De Rosalia, "Riflessioni sul concetto ciceroniano di amicizia", pp. 3-10

29 Madrid, Ediciones Clásicas, 1997.

30 Madrid, CSIC (Alma Mater), 1995. 
como "vieja sirviente de la casa de mi ama", "vieille domestique de ma maîtrese" en la versión Louis Méridier ${ }^{31}$, aunque en la expresión griega, además del carácter doméstico, acentúa con el término $\kappa \tau \tilde{\eta} \mu \alpha$ el hecho de la posesión, es decir, de la cosificación de la persona. Tal vez la traducción más expresiva sea de la Arthur S. Way ${ }^{32}$ : "O ancient chattel of my mistress home", que establece el vínculo con la "esclavitud mercancía", chattel slavery.

Aristóteles sabe que hay un tipo de democracia en que los pobres participan porque lo necesitan para ser libres (Política, III 5, $3=1278 \mathrm{a} 6-11$ ) y otro en que sólo participan los poseedores de hópla, los agricultores que pueden proporcionarse el armamento hoplítico, que es el tipo que los antiguos llamaban democracia (Política, IV 13, $7=1297 \mathrm{~b} 1-2)$. Se trata de la recuperación del sistema en que se identificaba ciudadanía, milicia y posesión de la tierra. Por ello, lo que deriva de todo esto es que un esclavo no es sólo la persona que se ha rebajado a tal situación debido a razones históricas; un esclavo no es la persona que ha caído en dicho estatuto legal; un esclavo lo es debido a su propia naturaleza en relación con el trabajo. Las afirmaciones referentes a las habilidades y aptitudes del cuerpo son las que realmente establecen la diferencia. De hecho, la naturaleza que se considera como más propia del esclavo es no sólo la que deriva de la guerra o del comercio, que es lo que definiría la situación del esclavo como cautivo o como artículo de comercio, lo que se relaciona normalmente con la naturaleza del bárbaro, sino la de todos aquellos cuya actividad está limitada a la utilización de sus cuerpos (I 5, $8=1254 \mathrm{~b} 15$ ).

El mismo Aristóteles, en Retórica, I 5, 7 = 1361a11-15, reconoce la importancia de la moneda en la evaluación de la riqueza, junto a los muebles, los esclavos y el ganado, como se ve igualmente en Jenofonte, Económico, III 4, y en Lisias, V En defensa de Calias, 3-5. El papel de los mercados parece haberse acentuado con las prácticas del siglo IV, tanto en los puertos como en las ágoras, donde abundan productos como los cereales, la cerámica, los metales, los textiles, la sal y los esclavos. La diferencia estriba en que ahora las fuentes de los esclavos no son sólo los prisioneros bárbaros transformados en mercancía.

\section{La visibilidad del esclavo}

Los espacios de la representación contribuyen a conocer los esquemas mentales que subyacen a la dependencia: el cuerpo del esclavo funciona como espacio de la representación y representación del espacio. La clave yace en la visibilidad y la invisibilidad del cuerpo del esclavo, según los ámbitos de la Geografía cultural. Las diferencias de los cuerpos serviles fueron objeto de análisis por Aristóteles. La representación tiende a la objetivación, a través del uso de rasgos muy marcados en las figuras de los dependientes, lo que se complementa con el contrapunto de la posición invisible de los esclavos en la vida real. Tal fue el contenido de la intervención en el coloquio GIREA 2012 de Marie Claude Charpentier. La mencionada perspectiva será publicada en las actas de dicho coloquio ${ }^{33}$ de la que he aquí un resumen previo:

\footnotetext{
París, Les Belles Lettres, 1961.

Londres, Heineman/ Harvard University Press, 1912 (LCL).

A. Beltrán, I. Sastre y M. Valdés (dir.), Actas del XXXV coloquio del GIREA. Los espacios de la esclavitud y la dependencia desde la Antigüedad, Besançon, PUFC, 2015, (El artículo no se publicó finalmente en las actas).
} 
“Le corps de 1'esclave en Grèce ancienne: Espace de la représentation ou représentation d'un espace?" par Marie- Claude Charpentier (Université de Franche-Compté) y F. Barthe-Deloizy (Université Jules Verne, Picardie):

Nous sommes donc parties en quête de ce corps dénié à travers le champ des représentations. Comment et où le corps de l'esclave est-il montré ? Quels sont les signes, les marqueurs corporels de l'esclavage? Comment reconnaît-on l'esclave dans les représentations figurées ou discursives ? On mettra en évidence un gradient de visibilité/invisibilité du corps de l'esclave à partir d'un corpus de textes et d'iconographies choisis ${ }^{34}$.

Con tales presupuestos se profundiza en la capacidad de los antiguos para percibir la personalidad de los esclavos a través de la percepción de los cuerpos de éstos. Con ello se permite indagar en la realidad esclavista tanto como en su función en el conjunto de la sociedad a través precisamente de la forma de representación y percepción del cuerpo.

Múltiples referencias aparecen en la literatura del siglo IV, indicativas incluso de un trato violento, como en el caso del "inoportuno" de Teofrasto, Caracteres, XII 12, que cuando alguien azota a su esclavo le cuenta cómo a él se le suicidó un esclavo al que había corregido de esa manera. Menandro en Perintia, 8, tomado de Suda, $s$. $u$. $(\text { Arnott })^{35}$, utiliza directamente $\sigma \omega ́ \mu \alpha \tau \alpha$, "cuerpos", para referirse a los esclavos domésticos. Tal mentalidad se compadece con la práctica de la violencia ante un cuerpo como objeto.

Los mercenarios de Éumenes, en un momento en que éste no podía pagarles el misthós, se sintieron muy satisfechos cuando el jefe decidió repartir el botín y las tierras, con sus esclavos incluidos, entre los soldados que se apoderaran de ellos, lo que le hizo ganar una fuerte adhesión en el ejército (Plutarco, Vida de Éumenes, 8, 9-11). Los esclavos, como objetos, son objeto del reparto del botín.

Esclavos como cuerpos son asimismo objeto de la atención de Polibio, XII 16, 5 , en que se refiere a las leyes de Zaleuco, en un capítulo que trata sobre el esclavo raptado del domicilio; en II 6, 6, se establece una contraposición entre " $\varepsilon \dot{\varepsilon} \lambda \varepsilon v ́ \theta \varepsilon \rho \alpha$

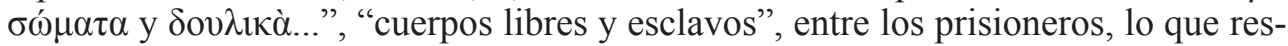
ponde a diferente tratamiento de los mismos.

La esclavitud como mercancía vuelve a crecer entonces a partir de la Paz de Apamea y el final del Imperio seléucida en 188, junto con la presencia del mercado en la isla de Delos, que funcionaba sobre todo como lugar de trata de esclavos controlado por Rodas. Estrabón dirá (XIV 5, 2), ya en época romana, que allí se intercambiaban a diario decenas de millares de esclavos. El final del mundo helenístico significa un renacimiento de las formas de dependencia puramente esclavistas, a costa de las formas que se habían desarrollado a partir de la crisis de la pólis como unidad política protagonizada por los ciudadanos, sobre todo en el caso dominante representado por Atenas y especialmente por la Atenas democrática. Los cuerpos esclavos protago-

34 "Nuestro estudio consiste en la búsqueda de ese cuerpo negado a través del campo de las representaciones. ¿Cómo y dónde se muestra el cuerpo del esclavo? ¿Cuáles son los signos, los marcadores corporales del esclavo? ¿Cómo se reconoce el esclavo en las representaciones figuradas o discursivas? Se trata de poner en evidencia el grado de visibilidad/invisibilidad del cuerpo del esclavo a partir de un corpus de textos y representaciones elegidos".

35 Menander, II (LCL), Cambridge, Mass.-Londres, Harvard University Press, 1996, ad loc. 
nizan un proceso de expansión en correspondencia con la época de expansión del imperialismo romano, que afectó como elemento transformador sobre todo al mundo griego. Aquí fue donde las transformaciones desde el campesinado dependiente, los "vientres" de Hesíodo, a la dependencia de los laoí como campesinos colectivamente sometidos, "libres sin derecho", habían sido más patentes. El protagonismo del cuerpo en el proceso resulta significativo del mismo proceso histórico del Arcaísmo al Helenismo. La intervención romana introducirá una significativa recuperación del momento más intenso de la explotación del cuerpo como puro objeto de cambio a partir de las condiciones de la guerra.

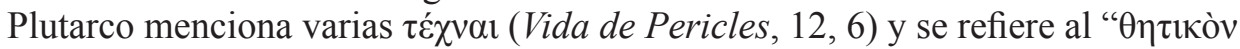

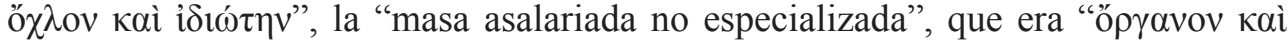

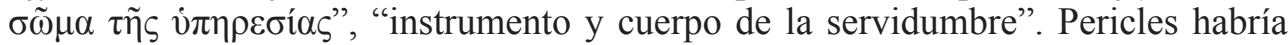
organizado así a la masa popular dentro de su sistema político ${ }^{36}$.

\section{La estabilidad social helenística}

La novedad del Mundo Helenístico con respecto a las relaciones de intercambio anteriores reside en el monopolio de las grandes casas reales ${ }^{37}$, que afectaba especialmente a la producción de las minas, donde la dureza de las condiciones de vida de los esclavos servía a Posidonio, recogido por Diodoro (III 12) (38 $^{38}$ como ejemplo de un sistema que era necesario reformar.

Diodoro Sículo III 12, 1:

En torno de los límites (eschatiás) de Egipto y la proximidad de Arabia y Etiopía hay un lugar que tiene muchas grandes minas de oro y se obtiene mucho con mucho sufrimiento y mucho gasto. En una tierra negra por naturaleza y con derivaciones y venas de mármol que sobresalen por su blancura y superan por su brillo a todas las naturalezas relucientes, los que se empeñan en las labores mineras preparan el oro con la masa de los trabajadores. 2 Pues los reyes de Egipto a los condenados por malhechores y a los prisioneros de guerra, además de los que caen por acusaciones injustas y son entregados a las prisiones por su soberbia, a veces a ellos, a veces también con toda su parentela, los reúnen y los entregan a la mina de oro, al mismo tiempo por tomar venganza de los acusados, pero al mismo tiempo por obtener grandes ganancias a través de sus trabajos. 3 Pero los entregados, que son muchos en número, todos encadenados con grilletes, se empeñan en los trabajos constantemente por el día y durante toda la noche, sin tomar ningún descanso, apartados celosamente de toda huida. En efecto, sobre ellos están las guardias formadas por soldados bárbaros que emplean diferentes lenguas de modo que nadie por compañerismo y compasión puede corromper a ninguno de los vigilantes.

Sigue en III 13, 3:

P. A. Stadter. A Commentary on Plutarch's Pericles, University of North Carolina Press, 1989, ad loc.

37 E. Will, "Le monde hellénistique", en E. Will, C. Mossé, P, Goukowsky, Le monde grec et l'orient. II Le IVE siècle et l'époque hellénistique, París, P.U.F., 1975, p. 537.

38 Traducción propia. 
Pues no obtiene perdón ni descanso en absoluto el enfermo, ni el mutilado, ni el que ha envejecido, ni la debilidad de la mujer, todos son coercionados ( $\dot{\alpha} v \alpha \gamma \kappa a ́ \zeta o v \tau \alpha \iota)$ a latigazos a esforzarse en los trabajos, hasta que abatidos mueren en las coercio-

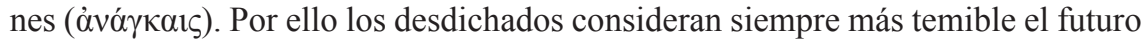
que el presente a causa de la enormidad de su castigo y más deseable la muerte que vivir.

Pólux, III 77-78, ya en plena época romana, pero como glosa a los textos de la literatura clásica ática, define $\operatorname{los} \delta o \tilde{\lambda} \alpha \sigma \omega ́ \mu \alpha \tau \alpha$, "cuerpos esclavos", como los cuerpos que son intercambiados por dinero y, tras enumerar una serie de términos para las distintas modalidades de vendedor, explica que no hay que referirse sólo a los $\sigma \omega ́ \mu \alpha \tau \alpha$, sino a los $\delta o \tilde{\lambda} \alpha \sigma \omega ́ \mu \alpha \tau \alpha$. El mismo Pólux, VI 127, se refiere al cuer-

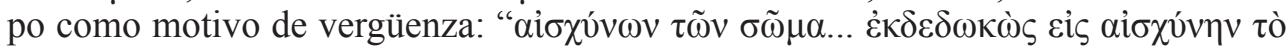
$\sigma \tilde{\omega} \mu \alpha$ ". Lo relaciona con el Gorgias platónico (494e) y su referencia a la obscenidad

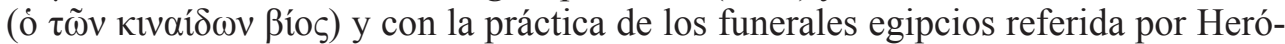
doto, II 78, de mostrar un cadáver a los presentes, todo ello a propósito de la referencia de Ilíada, I 115, al cuerpo de Clitemnestra en comparación con el de la esclava

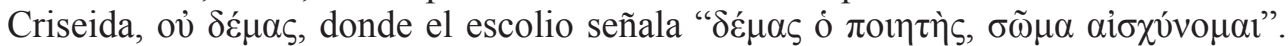
Parecería una palabra vergonzante, como se ve también en las palabras citadas como

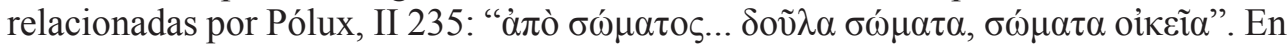
III 78 Pólux es más explícito, al tratar al mismo tiempo de introducir una matiza-

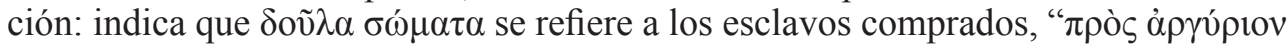

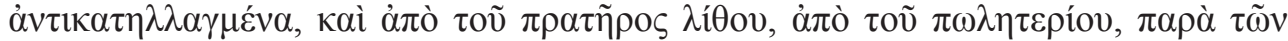

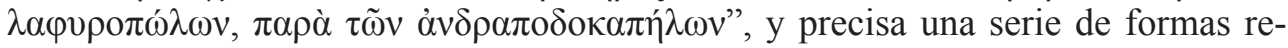

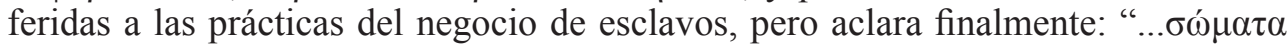

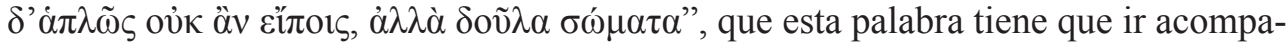
ñada del adjetivo correspondiente para referirse a los esclavos. El Dictionaire étymo-

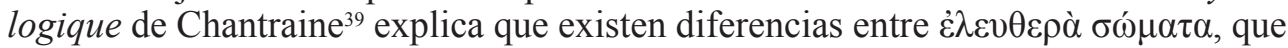

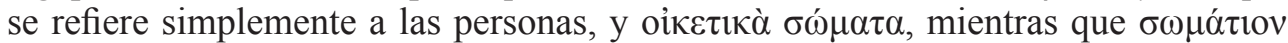
se refiere normalmente al esclavo. El término también alude a animales o cuerpos miserables, entre otros referidos a cuerpos no humanos.

\section{Conclusión}

Desde el principio, parece notarse una tendencia a identificar a los dependientes con su cuerpo o partes de él. En general, tal tendencia es síntoma de la misma cosificación de los humanos sometidos. Por ello se hace preciso en los momentos indicados señalar que puede haber "cuerpos libres", lo que sólo se explica por la tendencia dominante a marcar la diferencia, muy bien expresada por Aristóteles. El libre, ciudadano, el auténtico miembro de la comunidad con derechos, se caracterizaría por las virtudes que corresponden más bien al espíritu. De esta manera en el mundo de los esclavos se sustenta gran parte de la ideología dualista que caracteriza la historia del pensamiento occidental. Por ello también, las virtudes del cuerpo de los libres, las que se manifiestan en el atletismo y en la guerra, tienden a identificarse con las

\footnotetext{
P. Chantraine, Dictionnaire étymologique de la langue grecque, Paris, $2009^{9}$, s. u.
} 
virtudes propias de la areté, rasgo monopolizado en principio por el héroe aristocrático, difundido luego entre los miembros de la comunidad ciudadana, cuanto ésta se convierta en la heredera ideológica del héroe homérico, cuando el mito heroico se adapte a las necesidades del ciudadano de la pólis, fenómeno que se transparenta sobre todo en la tragedia. 